\title{
Article
}

\section{The state of play: how commensurate are BTECs and A-levels in sport and physical education}

Spence, S., and MacNamara, Á.

Available at http://clok.uclan.ac.uk/22737/

Spence, S., and MacNamara, Á. ORCID: 0000-0002-8110-6784 (2018) The state of play: how commensurate are BTECs and A-levels in sport and physical education. Research in Post-Compulsory Education, 23 (2). pp. 231-248. ISSN $1747-5112$

It is advisable to refer to the publisher's version if you intend to cite from the work. http://dx.doi.org/10.1080/13596748.2018.1444391

For more information about UCLan's research in this area go to http://www.uclan.ac.uk/researchgroups/ and search for < name of research Group>.

For information about Research generally at UCLan please go to http://www.uclan.ac.uk/research/

All outputs in CLoK are protected by Intellectual Property Rights law, including Copyright law. Copyright, IPR and Moral Rights for the works on this site are retained by the individual authors and/or other copyright owners. Terms and conditions for use of this material are defined in the policies page.

\section{CLoK}

Central Lancashire online Knowledge www.clok.uclan.ac.uk

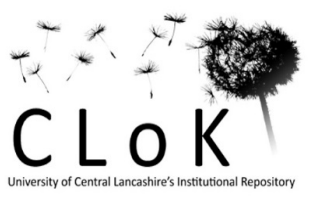


The State of Play: How Commensurate are BTECs and A-Levels in Sport and Physical

\section{Education}

Steven Spence \& Áine MacNamara

Institute of Coaching and Performance, University of Central Lancashire

Running Head: The State of Play in Talent Identification and Development 


\begin{abstract}
The somewhat forever-changing landscape of education in England has recently challenged the post-16 sector in new ways with funding and a knowledge-based curriculum just some of the new initiatives institutions must acclimatise to. Sport provision, a generic term used in this paper to encompass level three sport and physical education (PE) programmes, is not in limbo, but certainly faces challenges. This research focused on exploring the current 'state of play' of post-16 sport provision. Thirteen semi-structured interviews were carried out on teachers focusing solely on the A-level and BTEC National routes. Interviews were recorded and transcribed verbatim. The data were analysed using the six phases outlined by Braun and Clarke (2006) in the form of a thematic analysis. The main findings were that the content is perceived to be challenging due to the depth and detail of knowledge required on topic areas investigated on the A-level route, in contrast to the breadth, related to the number of units of study on the BTEC National programmes. Practical knowledge also emerged as a key theme with results indicating a diminished importance of the practical aspects of both programmes and conflicting views were evident on how practical knowledge should be assessed, with some preferring the grading of practical performance only and others preferring wider aspects of performance to feature in the grade awarded. Finally, post-16 options in sport and PE were perceived to be 'a positive thing' but the caveat with this is the concerns regarding programme symmetry and how commensurate respective programmes are.
\end{abstract}

Key words: Post-16, Sport and Physical Education (PE), Further Education (FE), Knowledge, Practical Performance. 


\section{Introduction}

Sport is a powerful tool in society and has many different applications within educational settings although, in terms of educational merit, knowledge and learning sometimes appear to receive a lower prioritisation in favour of being active (Nyberg and Larsson, 2014;

Quennerstedt, 2013). Research has also indicated that students view physical education as a 'break' from the academic and 'serious' aspects of school life (Coulter and Ni Chroinin, 2013) and this view of sport as a non-academic subject has certainly been the case in school sport provision with many physical education teachers questioning their role in the curriculum (Houlihan and Green, 2006). With government policy also appearing to shift to a knowledge-based outlook with a heavy focus on English and maths in post-16 education, physical and sports educators are right to be pensive in regards their futures. Further challenges include a move to a linear model for the A-level PE programme (Association of Colleges, 2015), and a revamp of the BTEC Sport programme to include extended content, stricter rules on submissions and resubmissions, and the inclusion of examinations. It is also evident that there is a general paucity of research into the programmes in sport and PE in the post-16 domain with much of the research carried out in the primary or pre-16 school environments. With this in mind the aim of this study was to investigate the commensurability of the level three BTEC Sport programmes with A-level PE.

The post-16 provision for sport spans a wide breadth of providers under the umbrella of further education (FE). The two most common of these in the FE sector are General Further Education Colleges (GFECs) and Sixth Form Colleges (SFCs) with the former greater in number by over one hundred (Prospects4Sport, 2010; Stoten, 2014). In most cases, GFECs offer a wider curriculum and cater for all levels of sport provision compared to SFCs. In contrast, SFCs 
deliver principally 16-19 provision along a more classical academic route. As such, the complexity of the landscape is considerable with a myriad of courses making up the possible curriculum offer in post-16 education including both the academic route of A-level and a significant number (over 300) of vocational programmes awarded by twenty-six Awarding Bodies (Prospects4Sport, 2010). This provision is currently under review by the government who are proposing a more streamlined system comprising two distinct pathways; 'academic' and 'technical' routes. The planned technical route is to have fifteen specialist pathways to improve the rigour of the current education system and deliver a world-class technical system (Department for Education and Department for Business Innovation and Skills, 2016). This is of interest as it raises questions regarding programme commensurability as both the level three BTECs in sport and A-level in PE will fall under the academic route and accrue points for university (Kelly, 2016).

At advanced level study (level three), the pathways currently fall under programmes typically classified as academic or vocational. At present, four different awarding bodies offer GCE Alevel programmes in Physical Education: AQA, OCR, Pearson Edexcel and WJEC. A GCE Alevel is also offered in Sport Science and the Active Leisure Industry by Council for the Curriculum, Examinations and Assessment CCEA (Ofqual 2015). There are currently twentynine different options for vocationally-related qualifications (VRQs) at level three with OCR and Pearson the largest providers offering several study programmes (Ofqual 2015). This brief mapping and overview of the post-16 educational terrain underlines the complex and at times confusing nature of options and choice available and the implications of such choices. This variety could be perceived to be positive as it plays to the strengths of the student, and potentially develops them for life after post-16 education. However, further exploration of this, especially from the perspective of those who deliver the course, is needed. 
With the dual academic and vocational study options classified on the Regulated Qualifications Framework (RQF) at level three the focus of this research was to gather the perceptions of those who deliver A-level PE, BTEC Sport or a combination of both to compare and contrast the parity of the respective programmes. First, with regard to GCE A-level, these programmes are delivered over a two-year period; on completion of year one students are accredited an A/S and on completion of year two (A2) the full A-level, although a linear model (exams in year two of an A-level programme determine the final grade awarded) is currently being implemented. While there are slight nuances between the governing bodies, the structure of the A-level PE programmes is similar across all awarding bodies, although the specific focus for this research is the AQA PE A-level. Four units comprise the full award with assessments based around a combination of exams, internally set assessments that are then moderated externally, and practical assessments. Grade classifications are then set from A* to E for the A-level. Each grade is then converted into a set number of UCAS points, for example, an A* is the equivalent to 140 UCAS points (UCAS 2015). This programme of PE study is taken with other A-level subjects and the delivery time per week reflects this.

In comparing VRQs to GCE A-level, these programmes of study can again consist of subdivided options, and thus workloads, but more options in terms of the choice of units are available than A/S and A2. An example of this is the Pearson BTEC which is based on credit values, although this is also currently under transition. Most units are worth ten credits although on the Sport (development, coaching and fitness) pathway the first two units are worth only five credits. This then leads to the qualifications being split by the amount of credits completed: for example, the certificate is 30 credits (four units on sport; three units on sport science); a subsidiary pathway is 60 credits (seven units on sport; six units on sport science); a 90 credit diploma (10 units on sport; 9 units on sport science); a 120 credit diploma (ten units on sport; 
nine units on sport science); and, the full extended diploma (19 units on sport; 18 units on sport science). In terms of unit options, smaller programmes offer less unit choice, and all programmes require core units to be studied.

In particular contrast of the BTEC to the GCE pathways is the nature of the development of the units and unit assessments. To date, the centres themselves devise the assignments, and thus also the re-assessments. The fact that BTEC programmes do enable resubmissions is a contrast to the A-level PE option and it will be of interest to gather teachers' perceptions on this. They are also graded and moderated by the centre, which currently must have one of their staff complete Lead Internal Verifier (Lead IV) training. If the individual is successful then the centre running Level Three programmes might not be externally verified for three years; if the individual is unsuccessful on the Lead IV training then they will be externally verified every year until this is completed (Pearson 2015). This is set to change in the near future with a move from the Qualifications Credit Framework (QCF) to the National Qualification Framework (NQF) which will more than likely mean that centres will be externally verified every year. This is very interesting and certainly begs the question as to why this is to be put in place. One reason could be that the BTEC programmes are now focused on preparing students for university which never used to be their key priority. However, with the dramatic increase in university entrants, a rise of 302 per cent studying BTECs and A-levels combined, and 182.5 per cent entering following BTECs only between 2010/11 and 2012/13, this shift to a more robust checking of standards seems well-timed (Kelly, 2016, 3). The planned change to the NQF and more rigorous external checks may also be to guard against the increased drop out, and lower degree classifications of those entering university through BTEC programmes although claims that 'BTECs set students up for failure' (Henry, 2014, 1) may be a little hasty. However, these changes further enhance the need for this study as a starting point to gather 
initial teacher perceptions. This process has already started on level two sport programmes. Similar to the GCE pathways is the translation of BTEC grade output points into UCAS points. An example of this would be a DDD profile on the extended diploma pathway being the equivalent to 360 UCAS points. Akin to the A-level this is also currently being developed but the conversion of qualification grade to UCAS points is still the same principle. Finally, the Pearson BTEC can be studied as a whole programme of study. Thus, a student can study an extended diploma (19 or 18 units) over a two-year period whereas on the GCE pathway the Alevel in sport is normally studied alongside other subjects, for example English, maths, or psychology.

With the above in mind there are a range of issues that merit consideration. First, with the content of both the VRQs and GCE programmes, it is important to remember that these qualifications are standardised on the RQF as level three programmes, so it would be expected that the content for both pathways has a measure of equivalence. The problem that arises is how this equivalence is reached across the two programmes. A logical step would be to examine the perceptions of those delivering A-level PE and BTEC Sport programmes to gain insight into how this commensurability may be achieved. This could include stakeholders' perceptions regarding the assessment and grading of both pathways and the output conversion into UCAS points. Currently, the VRQs and GCE programmes convert to exactly the same amount of UCAS points per programme size. What this means is that the GCE A-level provision is the same size as a Subsidiary Diploma and both equate to a maximum of 140 UCAS points for an A* or Distinction* (D) grade respectively. However, the GCE and VRQ pathways have fundamentally different aims. By nature, VRQs are designed to be more vocational but the amount of entries to universities from these pathways, as discussed earlier, is on the increase and would suggest that a motivation of people studying these programmes to 
move directly into a vocation is not the case and more students are studying these BTECs to progress to university (UCAS 2015). This then creates implications in terms of programme symmetry and progression routes when two programme pathways enable the same progression routes.

However, in terms of university attainment, does the programme studied at post-16 impact on final outcomes when at university? Data suggests this is the case at present with non-retention rates higher for those studying BTECs compared with A-levels, with the lowest success at Russell Group institutions (58.5 per cent) (Kelly, 2016, 19). Therefore, it is important to examine how commensurability between programmes can be achieved whilst keeping a variety of curricular offerings. One final caveat is to switch the focus to the institutions and teachers at universities and ponder whether they are fully aware of their role in meeting the needs of students from an applied background (Kelly, 2016). The blame may not solely lie with the programme of study and the ability of the students, it could also lie with the teachers at university.

Understanding and managing potential tensions between different curricular models, and changes in the operationalization of these, should be a priority. Managing and understanding these tensions however requires an understanding of the perceptions of the stakeholders who deliver post-16 sport provision and their experiences of the process. Of course, the limitations of this type of methodology must be acknowledged (e.g., confirmation bias based on the individual's experience, recall bias) but does represent a useful starting point to gain rich data about post-16 sport provision from the perspective of key stakeholders. Reflecting these issues, two research questions were proposed: 
The specific questions addressed were:

1) What are the operational issues in practice of both A-level PE and BTEC Sport programmes?

2) What are the potential benefits and constraints of having a variety of programmes with similar progression outcomes in post-16 sports education?

\section{Methodology}

The methodological approach for this piece of research was arrived at due to its explorative nature. The investigation of perceptions meant that knowledge had to be derived and understood in a particular paradigm. The belief system pertinent to this research is that understanding how participants construct the world around them would hold the key to unearthing 'truths' and new knowledge required for this study to build new theories valuable for practice settings (Giacobbi, Poczwardowski and Hager, 2005). This meant that the understanding and realisation of knowledge in this research was to be gathered through social constructions, where meaning in the post-16 curriculum is best understood by the individual ideas and opinions of the participants in the study. This led to the ontological position of constructionism because meaning and phenomena are accomplished by social actors' understanding reality through their own perspective (Bryman, 2012). This construction of reality thus gives a paradigm for how we see and understand the world due to the focus on how individuals make sense of the world through their own construction of reality (Atkinson, 2012). It is acknowledged that individual constructions will be influenced by participants' own experiences and ongoing embodied subjectivity. For example, an interviewee may have studied A-level PE themselves which influences their perceptions of that and other curricular models. This embodied subjectivity (Smyth, Mooney and Casey, 2014) could also include views on 
ability which can directly impact the views of what students can, and cannot, achieve (Hay and Hunter, 2006). In guarding against this, the interview questions were based on each participant's teaching experiences of the respective programmes and not their own previous study experiences.

This understanding of knowledge means that the epistemological underpinnings of interpretivism were relied upon for this research study. In this way the knowledge each participant has on the BTEC or A-level programmes is best represented through hermeneutics (interpretation of human action) and knowledge gained through the lived experiences and views of the participants (Bryman, 2012; Grant and Kluge, 2007). This understanding of both reality and the formulation of new knowledge invariably means that the driving force to answering the research questions was understanding knowledge as created by those who were sampled for the research. This led to a methodology that was qualitative in nature and inductive in process meaning that the observations (through interviews) within the research guided the development of new knowledge pertinent to the research questions.

Semi-structured qualitative interviews were employed as this approach allowed for the thoughts, feelings and opinions of the participants to be captured in line with the research aims and underpinning paradigms used. To fully understand the post-16 sport curriculum and understand the current 'state of play' theory was required to be generated from those who are actively involved in the day-to-day delivery of such programmes. Interviews enabled this knowledge to be captured and reflected upon prior to meanings to be made from the data. 
Semi-structured interviews were based on an interview guide produced around the research questions which were developed by the researchers' own experiences but more importantly literature, practice and policy reviewed. In this way the researcher became theoretically sensitive and developed insight into phenomena and the interpretation of meanings from the data (Jones, Brown, and Holloway, 2013). The interview guide was based around the following ideas but enabled a flow and exploration at all times:

1) The content of the respective pathways,

2) Grade parameters and conversion into UCAS points,

3) The aims of both pathways in relation to progression possibilities,

4) The appreciation of the practical elements on such pathways,

5) The benefits and limitations of having options at level three.

\section{Procedure}

Interviews were carried out at the host colleges at a place and time chosen by each participant. This was to give a freedom and security to the interviewee and enable them to feel comfortable during the interview. Also, prior to each interview, email conversations and telephone calls were carried out in order for the initial relationship boundaries to be relaxed. Each participant also signed a consent form and research information sheet.

\section{Participants}

Due to the specific criteria required purposive sampling was used to give clear inclusion criteria for this research study. These criteria are detailed below: 
1) Must have more than six months' experience delivering the respective courses and be either a lecturer or manager within the area of sport. This range of experience may unearth additional insights between teachers who have delivered the BTECs or A-levels.

2) Must teach a minimum of three hours per week on at least one sport programme. This decision was taken to guard against a teacher who may teach just one session a week along with other subject areas; for example, maths as part of a sessional contract and the requirements of a college.

3) Must be employed at a general further education college (GFEC) or sixth form college (SFC)

As is the case for many qualitative studies, the results from this study are difficult to generalise to the wider post-16 community (Yin, 2014). However, purposive sampling was used to represent the actual population frame in relation to the ratio of SFC to GFEC. This meant that two GFECs and one SFC were used as part of the data collection. In total, thirteen interviews were carried out lasting approximately 20-25 minutes each not including introduction and debriefing phases. The average experience of the participants was $10.9( \pm 9.4)$ years. Two participants had exclusively delivered A-level provision, five had delivered on both A-level and BTEC programmes and six on BTEC programmes only. This sampling reflected the purposive approach and it is acknowledge that more data will be collected on BTECs due to the increased number of these participants in the study. This is a limitation as substance could potentially be influenced by the number of people interviewed.

\section{Data Analysis}


The thirteen interviews were transcribed verbatim. Data was analysed using the six phases outlined by Braun and Clarke (2006) in the form of a thematic analysis. This method of analysis not only enabled the development of clear themes, which is often overlooked as the cornerstone of all qualitative analysis methods, but also matched the philosophical and methodological underpinnings of this research. In following the guidelines set out by Braun and Clarke (2006) an inductive analysis was employed and themes were created which represented findings across all thirteen interviews. The first step in creating the themes was the familiarisation phase. This was carried out when reading, re-reading and transcribing the interviews. Phases two and three created codes and then grouped similar codes in order to start seeing themes across the data set. Examples of this was how many codes in relation to content could be placed into a 'challenging content' group of codes. The final steps then enabled clear themes to be reviewed and named, revisited, checked and consolidated prior to the completion of the thematic analysis.

\section{Establishing Trustworthiness}

Firstly, pseudonyms of the colleges and participants were used to guarantee confidentiality when reporting the data in the findings and discussion sections. This was used so participants felt comfortable in giving their uncensored views and opinions, which in-turn, increased the validity of the data gathered during the interviews.

Reliability issues with qualitative data analysis are not uncommon and in order to reduce this a mix of the strategies were employed (Walton and French, 2016; Raufelder et al., 2016). At every stage of the thematic analysis a collaborative approach was utilised to check, compare 
and voice opinions regarding the creation of themes and sub-themes prior to the completed analysis.

\section{Results and Discussion}

On completion of the thematic analysis (Braun and Clarke, 2006) three main themes were identified. Each of these are presented below and exemplar quotations are used throughout to support the findings.

\section{Theme 1 - Content}

The content of any programme is what must be covered as part of the teaching syllabus for a respective programme. Teachers do have scope to plan how they wish to cover the content, but all programmes are specific in what must be covered. Although the content of both the A-level and BTEC options were discovered to be represented as challenging there was a clear difference as to why this was the case. The A-level was viewed as being very challenging due to the depth of knowledge covered within the syllabus. Mark, who has five years of experience and currently works at a SFC teaching both A-levels and BTEC programmes stated:

'More often than not, the students that we have on our course, especially A-Level course, tend to say that the physical education course is the hardest subject because of the depth they are required to understand.'

This view was further endorsed by Luke, a teacher at a SFC with over nineteen years of experience teaching A-level sport who stated:

'...it's really challenging for some of them just quite a few of them are quite surprised by how challenging the depth and detail of the content is.' 
Reflecting on these statements, the A-level in PE is a challenging programme of study. The detail that is covered on topic areas is very challenging but in addition to this, students must demonstrate the application of this knowledge if they are to be successful. Within an exam environment, the ability to recall facts alone will not gain the highest marks. Instead, the highest achieving students will demonstrate an ability to evaluate and synthesise arguments that will gain greater marks. The importance of being able to think critically is vital for showing high levels of comprehension (Pithers, 2000). There is also the additional challenge of regulating one's learning effectively to be successful in examinations, with higher performing students being better judges of their learning (Hacker et al., 2000; Bol et al., 2005).

Conversely the BTEC was discovered to be challenging because of the broadness of the content. David, a teacher of four years on BTEC programmes and Niamh, a teacher with seven years of teaching BTEC programmes endorsed this view:

'Yeah, I think it's good. I think there's a good wide range of topics that they can cover. I also think it's quite useful that each institution can specialise their units from their speciality and subject areas.' (David)

and;

'...you study the science to sport, the anatomy, the physiology, other pathways like the biomechanics, the massage, there's so much to it and it's a complicated subject...'

(Niamh)

The data suggests that having options at level three is a positive and the BTEC pathway has its own challenge for students. Certainly, it introduces many topics, so a student may find an area of specific interest that they can progress on with. Having numerous ongoing modules also develops a student's ability to plan, organise and prepare for deadlines, which are vital at 
university. However, it could be argued that covering a greater range but with less detail, and having opportunities to upgrade assessments doesn't prepare an individual for university in the most effective way.

Consequently, data indicates distinct views across both programmes in terms of study requirements and content requirements, which causes challenges in the creation of clear content knowledge (Dyson, 2014; Ward, 2013). Depending on the programme studied, in this case BTEC Sport or A-level PE, there will be vast differences in content and how this was assessed. For example, the practical elements of the programmes are very different in what is required to be successful. Furthermore, on the BTEC, with many more units, more content will be covered than those studying an A-level in PE. If we then imagine two students aiming to progress into higher education at university following the completion of their post-16 programme it is possible that the content studied will have varied considerably. The A-level programme has always been in place for people who wish to progress to university, but growing numbers now enter following the study of BTEC programmes (UCAS 2017). Content variation was further discussed by Sally, a teacher on both A-levels and BTECs for fifteen years and Jack, a teacher of BTEC programmes for four years with experience of teaching degree level programmes:

'Mixed. The major difference I've noticed between A-Level and BTEC is the depth of content. The BTEC seems to be relatively superficial and they do a lot of work and a lot of assignments...' (Sally)

and; 
'I think preparing you for university, I think it's much better (BTEC) in terms of how to structure reports, how to reference and there are more topics that are covered that aren't covered at A-level.' (Jack)

This is of clear interest following the proposed government plans with new BTEC programmes in sport scheduled to fall under the applied general route and not on the technical route suggesting that university is a primary outcome following the study of a BTEC Sport programme (Department for Education and Department for Business Innovation and Skills, 2016). The content covered prior to university study is important as it should set prospective students up to succeed in higher education but the vast difference in perceptions of those interviewed for this research regarding content indicates that advantages and disadvantages could be a possibility, and this could prove problematic. Thought must be given to how indicative content is covered on whichever programme pathway is chosen and how the skills that accompany this knowledge are developed to help people progress to university. There is also an expectation on pre-university students to be fully aware of their chosen programme of study, utilise the information supplied by universities at open days and through their websites and match their knowledge and skills gained whilst studying in post-16 education to the most appropriate course. It would be worrying to block certain pathways into higher education on the basis of what was studied in further education, but it is fair requirement to accomplish study symmetry within post-16 options. This extends to students who leave education and move into work following the completion of their post-16 programme and further thought must be given to content coverage without reducing the options to students or demeaning the study of sport, $\mathrm{PE}$ and sport science as disciplines. Clearly the results here suggest distinct differences across varying programmes in terms of why the content is challenging for students. Although these perceptions are representative of the data gathered during the interviews they are also likely to reflect, in some way, the past experiences of studying, and interactions with other practitioners 
over the duration of their teaching career. The difficulty moving forward is to make sure that both options equip students with the right knowledge through content to enable them to progress onto future courses and careers based on their acquired knowledge. In addition to this is supplementing the development of content knowledge with skills that will help a student thrive, not simply survive when they progress to university or the world of work.

\section{Theme 2 - Practical knowledge}

This theme was evident across the data set and implied a cautious and concerned outlook on practical knowledge. This was evident across both the BTEC and A-level programmes. In terms of the importance of practical knowledge within the programmes of study at post-16 the data suggested an under whelming attitude towards it. It was evident that the amount (time), assessments and most worryingly in some cases students' attitude towards the practical aspects is reflective of the disengagement of practical knowledge within the programmes. Paul, with thirty-two years of experience teaching A-level programmes stated:

'Yes, a bit concerned because it's all knowledge base; it's all recall whereas I think in a subject like physical education you need to be appreciating the physical side of the subject and the practical side of the subject and that should be an important part of it and it's a diminishing part.' (Paul)

His views were further supported by David (4yrs, BTEC) and Chris, who has three years of experience delivering BTEC programmes:

'I think it's drifted below theory, but I would put it in equal if not more important, because they're the skills that are being used.' (David) 
'I think with it being sport, there's less and less importance being put on practical.

It echoes a worrying outlook for practical knowledge especially within a subject such as sport and physical education where there should be a clear representation of such knowledge. It is clear the BTEC and A-level have different approaches to practical success in terms of assessment. For example, the A-level offers grades for the quality of performance and the BTEC is more focused on the student's ability to reflect and analyse performance. However, the perceptions across the data set suggested concern towards practical aspects, whether that be on the BTEC or A-level pathway. Furthermore, the wider benefits of being active do not appear to be elevating the practical aspect of the programmes. With PE the only subject that develops the psychomotor, cognitive and social domains simultaneously (Rink, 1998) the themes evident in this study are worrying. Instead, data here suggests a lack of progress following Richard Peters' comments over 50 years ago:

'Curriculum activities, on the other hand, such as science, history, literary appreciation, and poetry are 'serious' in that they illuminate other areas of life and contribute much to the quality of living. They have, secondly, a wide-ranging cognitive content which distinguishes them from games. Skills, for instance, do not have wide-ranging cognitive content. There is very little to know about riding bicycles, swimming, or golf.' (Peters, 1966, 159)

Contesting the above quote and arguing the philosophical and ethical issues surrounding it are not the focus of this research; although it is difficult not to smile when history and literary appreciation is considered better for the 'quality of living' than being physically healthy. However, you could be excused for questioning the date as much of the statement is systematic 
of the current education system in England. Knowledge, and progress in the classical subjects such as English and maths have become the key driver of the education system in recent years, starting with the selection of Michael Gove as the education minister in 2010. Nicky Morgan and Justine Greening have continued with these plans in more recent years.

The findings would also support Houlihan and Green (2006) who found that PE teachers are questioning their role in the curriculum. This outlook is a concern and could be due to the overriding philosophical appreciations of knowledge and how there is often a separation of corporeal and cognitive knowledge (Light, 2014). The data indicated that the split of theory to practical has tipped further towards theory over many years and the onus is on the students to organise their own practical training and development. Clearly, theory is abundantly important and in no way is this questioned but concerns arise over how practical is now represented. It could also be postulated the focus of the government on the classical 'academic' subjects in recent years has heightened this dissonance for subjects with some basis on practical knowledge (Department for Education, 2012). This is in agreement with the findings of Nyberg and Larsson (2014) and also Quennerstedt (2013) who offer concern over the role PE has in the curriculum.

A further point for debate is the assessment of practical knowledge. In this case, practical is to do with some aspect of physical performance, not in the case of a theory lesson being delivered in a practical manner to enhance the learning experience of the students. What can only be described as a polarity of opinion was evident in terms of practical assessments. Jamie, with twenty-four years of delivering both A-levels and now more BTEC programmes, and Luke (19 years, A-levels) respectively commented: 
'If you go to an employer, 'Can you stand up in front of a group and deliver a good session? No, but I know what I'm doing wrong.' It doesn't quite seem right to me.' '...I'm not sure that's always brilliant, because you can be the worst coach in the world but leave with a Distinction in coaching. (Jamie)

and;

'Well it seems a bit odd doesn't it? I mean there's lots of practical situations within the BTEC students are assessed at but it's mainly leading, coaching and reflecting; not their actual practical performance.' (Luke)

Opposing this view was Paul (32 years, A-levels) and Claire, who has fifteen years of delivering A-levels primarily, but in recent years BTEC programmes as well:

'...not all people that study PE necessarily have to be top performers. They can still gain a lot from the subject even though they may not be a top performer. So that's a bit of a concern.' (Paul)

'...... and I like the fact that the practical element of the BTEC to the individual team sports they can still score highly, even without being the best performer in the world' (Claire)

The surprising aspect here was how those who delivered more on the A-level were not just restricted to the view that practical performance should be the only measure and vice versa in terms of the BTEC and non-direct assessment of practical performance. Although the data cannot be generalised outside of this study it is an interesting finding as A-levels grade on performance as opposed to the BTECs. 
These findings do bring out an interesting debate as to whether performance should be a key determinant for a grade. If so, those who can perform to a high standard will be at a considerable advantage, however university degrees and vocations in sport do not require performance to be excellent unless someone is a professional athlete, suggesting that assessing only through performance is not the most effective way to prepare students for the next stage of their lives. This also hinders those who are not top performers but have many other attributes which could enable them to excel in further study and a number of vocations.

As with the content, commensuration is required on how practical is measured within the varying programmes. Several interviewees alluded to how high the grade boundaries are for the A-level pathway. The reflective aspect of practical performance within a BTEC, including the delivery of coaching sessions was also questioned by several interviewees. Primarily grades are awarded for 'independently' carrying out sessions but this does not necessarily guarantee a session that was delivered to a very high standard. Certainly, having broader aspects than simply practical performance measurement is a requirement for post-16 sport but care must be taken if practical is not to be undermined and viewed as an add-on to a course and programme. The worrying view that several interviewees commented on was how students' outlook on practical has changed in recent years suggesting that the importance of practical is reducing in the eyes of the students. One possible explanation for this is the requirement for students to stay in education until they are eighteen (Department for Education and Department for Business Innovation and Skill 2013) meaning some students may choose a sports programme out of necessity rather than choice. This could explain why those interviewed commented on 'different students'. In theory, although the numbers studying a sport or PE programme in post16 education has increased the data here suggests that this is not perceived as a positive as some students are not fully committed to the programmes. 
In relation to assessing practical performance the outcome of performance is heavily relied upon within assessments. This is logical progression and is not criticised but doesn't necessarily always give a full picture. The difficulty with assessing performance in other ways can be very problematic as can fully understanding physical knowledge (Polanyi, 1966; Light 2014). Within BTEC programmes performance is not graded but rather evaluations of performance and delivery of sessions is what distinguishes grades. The data indicated some support for this model, but some did prefer alternative methods. The emphasis on delivering coaching sessions or carrying out a fitness practical does align with programme aims but discrepancy is clearly held in regards the grading requirements of what 'quality practical is'. As Chris (3 years' experience, BTEC) alluded to, 'a student could be useless at the practical performance of a sport but still get the highest grade due to their ability to reflect on their performance and what makes a good performance'. Clearly, work is required to satisfy those delivering BTEC Sport or A-level PE that the different approaches to assessing the practical aspects of each programme are commensurate. However, the differentiated approach to assessing practical must be positive in principle as the arbitrary view of the best performers make the best coaches or teachers is clearly not the case.

\section{Theme 3 - BTEC vs A-level}

There is a myriad of different options for post-16 study in sport and PE with many of these courses offering very similar outcomes. Following the interviews at three different post-16 providers a clear theme of comparison between BTEC Sport and A-level PE programmes emerged. Although much comparison has factored in the two previous themes further comparison did emerge to show a clear pattern for what those teaching the respective 
programmes feel at the delivery level. Firstly, having study options at level three emerged as a clear positive:

'I think potentially (the pathways), they've got the potential to play to students strengths.......it's fantastic.' (Sally, 15 years' experience of teaching both programmes)

'I think it's great, some students are naturally more academic, and I suppose it depends on what area you want to go into.' (Niamh, 7 years' experience, BTECs)

'I think that the more ways that you can do a qualification and you've got to find, as a student, the best way to go and do it.' (David, 4 years' experience, BTECs)

Clearly many students enter the post-16 sector and having options available for different students gives those interested in further study and a potential career in sport a chance to achieve this. Throughout the data interviewees specified that students are different in terms of their starting points, their skill set, how they like to be assessed and prospective students should be able to 'play to their strengths'. One interviewee stated that wider cognitive skills such as maturity and discipline may develop in the post-16 years and having a variety of pathways would help students progress into higher education in the future, whereas, one limited option may not accomplish this. However, a caveat to having options is how commensurate each programme, awarding body and even institution are. This was a reoccurring theme within the data set and one which could prove problematic in finding a solution. Claire, Mark and Jamie offered the following:

'So if we're saying that a distinction is the same as an A at A-level, they might have done that work to a distinction level but do they know it?' (Claire, 15 years' experience teaching both A-levels and BTECs) 
'Well, so as I linked to before, how a Distinction* and an A at A-Level compare, I wouldn't say that they are equal.' (Mark, 5 years' experience teaching both A-levels and BTECs)

'In some institutions, yes. In other institutions, no. I think it's down to how it's delivered. I think in BTEC there is more scope for teachers to support the final outcome. That's probably a nice way to put it politically'. (Jamie, 24 years' experience teaching both A-levels and BTECs)

Getting the balance between options and standards is a difficult challenge with many influencing factors. Obvious discussion points were evident in the interviews across the two main programmes with conflicting views of final grade outputs and if they are a true reflection of what a student has done and is capable of. An A* on the A-level PE programme is equal to a $\mathrm{D}^{*}$ on a BTEC Sport programme and some questioned the equitability of this. Both programmes are currently going through changes and new specifications are ready for implementation in the coming years, but this is certainly a challenge for the post-16 provision. Also, the outcome of respective programmes and what each programme should enable progression onto is poignant. Likewise, is the addition of exams now incorporated into the level three BTEC programmes which is a new development. This may sacrifice the variety currently available for a greater validity of programme standards which did factor within this theme. Data suggested that there is less of concern regarding content but more of an issue in regards the equitability of the assessments. The new A-level has moved to the linear approach and means that one exam is now prominent after two years of study (Association of Colleges, 2015). If this is compared to BTEC on-going units and assessments are the delivery mode but resubmissions are still allowed. Those interviewed also intimated a cynicism into the potential standard differentials across teaching staff and institutions in regards the assessment levels on BTEC Sport programmes. 
The above only exemplifies the difficulty in getting the balance in variety of programme choices, with commensuration of standards to give students a good base to progress from. It was not the purpose here to make one programme appear better than another, or to influence policy in anyway but simply reflect the views and opinions of those delivering on the frontline. Clearly options are perceived to be a good thing, but this is evidently problematic. Furthermore, is the progression following the completion of respective programmes which requires consideration. If respective programmes are different in terms of content, assessment and programme aims then is there a requirement to re-evaluate the progression routes into higher education. This could become more pertinent with the proposed technical plan and how post-16 sport, PE and technical certificates will factor within the fifteen technical areas (Department for Education and Department for Business Innovation and Skills, 2016). Programmes which are on the technical plan will lead directly into working careers and other programmes, classified as academic or applied general will accrue university points on completion. Presently, it appears that all level three BTEC Sport programmes along with Alevel PE will be classified as academic or applied general routes, meaning a major aim of the programme is to support university progression. Currently, only massage therapy is scheduled to be embedded on the technical side where progression to employment is the focus. This again highlights the balancing act required to get programme variation and standards commensurate as reflected in the data.

A final consideration is when the new specifications are developed in the next five years how will they push knowledge further? More depth, more content to cover? The point is content knowledge is vital for all subjects, but are students becoming more intellectual if more is simply added to the content, the authors here would contest this in the belief that more information and more content does not equate to better thinking and more knowledgeable students. It is 
possible that other approaches and appreciations may have to be considered rather than the approach 'more to learn must mean more knowledge'. In many respects understanding what 'thinking is and does' to develop knowledge in education may be a focus of future debates (Cabrera, 2011). Irrespective of this, the study of sport and PE programmes of study in post-16 education must be respected. The data here offers a little concern, especially around the practical aspects of respective programmes.

\section{Conclusion}

The purpose of this study was to explore post-16 sport provision by focusing on how teachers perceive the current 'state of play'. The A-level PE and BTEC Sport programmes at level three were the focus of the study. Following a thematic analysis of the thirteen interviews it was found that across level three provision the content is perceived to be challenging. The content on the A-level was challenging due to the depth and detail that had to be studied in contrast to the broadness (number of units) of the BTEC Nationals. However, and in many respects quite natural a subtheme of this was content variance across the different programmes. Practical knowledge also emerged as a key theme. Firstly, results indicated a diminished importance of the practical aspects of both respective pathways and views on how practical should be assessed were conflicting, with some believing that grades should be awarded for the standard of practical performance whilst others preferring more variety in the grading of practical performance. Finally, post-16 options in sport and PE were perceived to be a positive but the caveat with this is the concerns regarding programme symmetry and how commensurate respective programmes are. 
Future research should focus on how practical knowledge is to be better appreciated in post-16 sport provision, with a focus on both teacher and student representations, and the impact of new government legislation in the delivery of lower level courses. 


\section{References:}

Association of Colleges. 2015. "Information for Schools and Colleges: Implementing A Level Reforms." February. Accessed August 7, 2017. https://www.aoc.co.uk/sites/default/files/A\%20Level\%20Reform\%20Guidance\%20Documen t.pdf.

Atkinson, Michael. 2012. Key Concepts in Sport and Exercise Science Research. London: Sage.

Bol, Linda, Douglas J. Hacker, Patrick O'Shea, and Dwight Allen. 2005. "The Influence of Overt Practice, Achievement Level, and Explanatory Style on Calibration Accuracy and Performance." The Journal of Experimental Education 73 (4): 269-290.

Braun, Virginia, and Victoria Clarke. 2006. "Using thematic analysis in psychology." Qualitative Research in Psychology 3 (2): 77-101.

Bryman, A. 2012. Social research methods (4th ed.). Oxford: Oxford University Press.

Cabrera, Derek. 2011. TEDx. Accessed 12 1, 2016. https://www.youtube.com/watch?v=dUqRTWCdXt4.

Coulter, Maura, and Deirdre Ni Chroinin. 2013. "What is PE." Sport, Education and Society 18 (6): 825-841.

Department for Education. 2012. Improving the quality of further education and skills training. 12th December. Accessed September 1st, 2014.

https://www.gov.uk/government/policies/improving-the-quality-of-further-education-andskills-training.

Department for Education \& Department for Business Innovation and Skills. 2016. "Department for Education." July . Accessed August 7, 2016.

https://www.gov.uk/government/uploads/system/uploads/attachment_data/file/536043/P ost-16_Skills_Plan.pdf.

Department for Education and Department for Business Innovation and Skill. 2013. Rigour and Responsiveness in Skills. England: DfE \& BIS.

Dyson, Ben. 2014. "Quality Physical Education: A Commentary on Effective Physical Education Teaching." Research Quarterly for Exercise and Sport 144-152. Vol. 82:2.

Giacobbi, P R, A Poczwardowski, and P F Hager. 2005. "A Pragmatic Research Philosophy for Sport Psychology." Sport Psychologist 19 (1): 18-31.

Grant, B, and M Kluge. 2007. "Exploring other body(s) of knowledge: Getting to the heart of the story about ageing and physical activity." Quest 59 (1): 398-414.

Hacker, Douglas J, Linda Bol, Dianne D Horgan , and Ernest A Rakow. 2000. "Test Prediction and Performance in the Classroom Context." Journal of Educatioal Psychology 92 (1): 160-170.

Hay, Peter J, and Lisa Hunter. 2006. "'Please Mr Hay, what are my poss (abilities)?: Legitimation of ability through physical education practices." Sport, Education and Society 11 (3): 293-310. 
Henry, Julie. 2014. BTecs 'set students up for failure' at university. Accessed October 15, 2017. https://www.thetimes.co.uk/article/btecs-set-students-up-for-failure-at-university360 grz7bt5x.

Houlihan, Barrie, and Mick Green. 2006. "The changing status of school sport and physical education: explaining policy change." The changing status of school sport and physical education: explaining policy change 73-92. Vol. 11, 1.

Jones, lan, Lorraine Brown , and Immy Holloway. 2013. Qualitative Research in Sport and Physical Activity. London: Sage.

Kelly, Scott. 2016. Reforming BTECs: Applied General qualifications as a route to higher education. Oxford : Higher Education Policy Institute.

Light, Richard Lawrence. 2014. "Mushin and learning in and beyond budo. Ido Movement For Culture." Journal of Martial Arts Anthropology pp. 42-48, Vol. 14, no. 3.

Nyberg, Gunn, and Hakan Larsson. 2014. "Exploring 'what' to learn in physical education." Physical Education and Sport Pedagogy 19:2 123-135 DOI: 10.1080/17408989.2012.726982.

Ofqual. 2015. Ofqual. 31 10. http://register.ofqual.gov.uk/Qualification.

Pearson. 2015. Pearson Qualifications . 3110.

http://qualifications.pearson.com/en/support/support-topics/quality-assurance/btecquality-assurance-handbook.html/Teacher.

Peters, Richard S. 1966. Ethics in Education. London: Allen \& Unwin.

Pithers, R T. 2000. “Critical thinking in education: a review." Educational Research 42 (3): 237-249.

Polanyi, Michael. 1958. Personal Knowledge-towards a post-critical philosophy. London: Routledge.

Polanyi, Michael. 1966. The Tacit Dimension. Chicago: Chicago University Press.

Prospects4Sport. 2010. The Future of Further Education Sport. England : Sport England, Association of Colleges.

Quennerstedt, Mikael. 2013. "Practical epistemologies in physical education practice." Sport, Education and Society 18:3 311-333 DOI: 10.1080/13573322.2011.582245.

Raufelder, Diana, Lisa Nitsche, Sven Breitmeyer, Sabrina Kebler, Elisa Herrmann, and Nicola Regner . 2016. "Students' perceptions of "good" and "bad" teachers-Results of a qualitative thematic analysis with German adolescents." International Journal of Educational Research 75: 31-44.

Rink, Judith E. 1998. Teaching Physical Education for Learning. 3rd. Boston: McGraw-Hill.

Smyth, John, Amanda Mooney, and Meghan Casey. 2014. "Where has the class gone? The pervasiveness of class in girls' physical activity in a rural town." Sport, Education and Society 19 (1): 1-18.

Stoten, David William. 2014. "Sixth form colleges: isomorphism, adaptation and the new education market." Research in Post-Compulsory Education 378-392, Vol. 19, No. 4.

UCAS. 2015. UCAS points. 31 10. https://www.ucas.com/ucas/undergraduate/getting-started/entryrequirements/tariff/tariff-tables/946. 
-. 2017. "ucas.com." 2 February. Accessed March 15, 2017.

https://www.ucas.com/file/92746/download?token=4lj-BMlr.

Walton, Peter D, and David P French. 2016. "What do people think about running barefoot/with minimalist footwear? A thematic analysis." British Journal of Health Psychology 21: 451-468.

Ward, P. 2013. "The role content knowledge in conceptions of teaching and effectiveness in physcial education." Research Quarterly for Exercise and Sport 431-440. Vol. 84.

Yin, R K. 2014. Case Study Research: Design and Methods. 5th. London: Sage. 